\title{
Clinical relevance of heparanase mRNA expression in bladder cancer and its usefulness as a detection marker in voided urine
}

\author{
WEI ZHAO ${ }^{1}$, XIN-SHENG WANG $^{3}$, HAI-TAO NIU $^{3}$, LI-LI WANG $^{2}$, BANG-MIN HAN ${ }^{1}$ and SHU-JIE XIA ${ }^{1}$ \\ Departments of ${ }^{1}$ Urology, and ${ }^{2}$ Docimasiology, First Affiliated People's Hospital of Shanghai, \\ Jiao Tong University, Shanghai; ${ }^{3}$ Department of Urology, The Affiliated Hospital of \\ Medical College, Qingdao University, Qingdao, P.R. China
}

Received November 20, 2008; Accepted January 22, 2009

DOI: 10.3892/mmr_00000104

\begin{abstract}
Heparanase is an endo- $\beta$-glucuronidase that can selectively degrade heparan sulfate glycosaminoglycans and that has been shown to play a role in tumor progression, metastasis and tumor angiogenesis. Previous studies have demonstrated that the overexpression of heparanase in human tumors facilitates their invasive activity, thereby enhancing tumor metastatic potential. We detected the simultaneous and significantly correlated overexpression of heparanase in the tissues and urine of patients with bladder cancer. Expression of heparanase mRNA in the tissues was significantly correlated with various clinicopathological factors, such as stage, histological grade, size, number, recurrence and lymph node metastasis. This was not the case in the urine. In addition, the relapse rate was significantly higher in the patients exhibiting heparanase mRNA expression than in the patients lacking it. Heparanase at the mRNA level had greater sensitivity in the detection of bladder cancer than cytology, and specificity for the marker was relatively high. These findings suggest that the overexpression of heparanase may influence various malignant behaviors in bladder cancer, and that the RT-PCR assay for heparanase mRNA is a promising non-invasive test with high sensitivity and specificity for the diagnosis of the disease.
\end{abstract}

\section{Introduction}

Bladder carcinoma is the second most common cancer and the second leading cause of death worldwide among malignancies of the genitourinary tract (1). It ranks eighth among all types of cancer in China, and has been associated with many

Correspondence to: Dr Shu-Jie Xia, Department of Urology, First Affiliated People's Hospital of Shanghai, Jiao Tong University, 100 Haining Road, Shanghai 200080, P.R. China

E-mail: yushi8026@hotmail.com

Key words: bladder cancer, heparanase, cytology, urine, diagnosis, RT-PCR pathogenetic factors $(2,3)$. Transitional cell carcinoma (TCC) accounts for more than $90 \%$ of bladder carcinomas. It can present as papillary superficial lesions with low malignant potential or as high-grade tumors that can be invasive and lethal. When bladder transitional cell carcinoma (BTCC) is detected during an early localized stage, the 5-year survival rate is $94 \%$. Once the disease spreads regionally or distally, the 5 -year survival rate drops to 49 and $6 \%$, respectively. Thus, it is critical to detect the early events in the recurrence of superficial cancer, before the cancer becomes muscle-invasive (3). At present, cystoscopy and urine cytology are the standard procedures for the diagnosis of bladder cancer. Cystoscopy is the mainstay for cancer detection, but the invasiveness of the procedure and the relatively inconclusive results obtainable in cases of cystitis are an issue. Cytology has high specificity, but is less sensitive - particularly in low-grade diseases (4). In view of these weaknesses, urologic research has focused on the development of urine tests that could serve as non-invasive surveillance tools. New and reliable non-invasive markers for bladder cancer detection therefore present new possibilities for the diagnosis, screening and follow-up of bladder cancer patients.

It is generally accepted that the basement membrane (BM) and exracellular matrix (ECM) act as barriers, playing a key role by preventing the invasion and metastasis of cancer cells (5). Over the past decades, studies of bladder tumor invasion and metastasis have practically focused on various proteases, the substrates of which are limited to the structural proteins of BM. However, few studies have focused on heparanase, the substrates of which are heparan sulfate proteoglycans (HSPGs) $(1,6)$. HSPGs are among the main components of $\mathrm{BM}$ and ECM, and play a physiological role as co-factors in many cellular processes, including cell-cell interaction and cell invasiveness (6). Heparanase, an endo- $\beta$-glucuronidase, can selectively degrade HSPGs and has been thought to play an important role in tumor progression, metastasis and angiogenesis (7).

In the present study, we examined the expression of heparanase mRNA in 28 normal urothelium specimens as well as in 55 bladder cancer and urine specimens from the same patients using semi-quantitative RT-PCR. The differential expression of heparanase mRNA was further analyzed, and 
its correlation with the clinicopathological characteristics of bladder cancer was discussed. Furthermore, we attempted to optimize an RT-PCR protocol for the sensitive non-invasive detection of heparanase mRNA in the urine of patients with bladder carcinoma.

\section{Materials and methods}

Tissue samples. Fifty-five bladder cancer tissue samples were obtained from 39 male and 16 female patients (median age 60.7 years, range $42-78$ years). The bladder cancers were histopathologically diagnosed as TCC. Staging of the tumors was carried out according to the TNM classification. There were $21 \mathrm{pT}_{\mathrm{a}-1}, 22 \mathrm{pT}_{2}, 10 \mathrm{pT}_{3}$ and $2 \mathrm{pT}_{4}$ tumors. Grading of the tumors was carried out according to the World Health Organization (WHO) criteria, with 15 cases being determined as $\mathrm{G}_{1}, 27$ as $\mathrm{G}_{2}$ and 13 as $\mathrm{G}_{3}$. Of the patients, 47 had primary tumors, while 8 were cases of recurrence. All patients were subjected to periodical follow-up. The mean follow-up time of the study was 20 months. Of the 55 cases, 21 developed recurrence. As a control, 28 normal tissue samples were obtained from patients undergoing cystoscopy. Immediately after surgical removal, tissues were snap-frozen in liquid nitrogen and maintained at $-80^{\circ} \mathrm{C}$ until use. All studies were approved by the Human Subjects Committee of the University of Bern (Bern, Switzerland).

Urine samples. Simultaneously voided urine samples were obtained from 20 patients with benign urologic diseases $(5$ with benign prostatic hypertrophy, 7 with urinary tract infections, 5 with ureteral stones and 3 with hematuria) and from 20 normal cases. All subjects provided $100 \mathrm{ml}$ morning voided urine for RT-PCR and cytological testing. Urine samples were centrifuged $(1500 \mathrm{x} \mathrm{g}$ for $10 \mathrm{~min})$ to remove the supernatant. The urinary sediment was washed twice with phosphate-buffered saline, $\mathrm{pH}$ 7.0. The sediments were frozen and stored at $-80^{\circ} \mathrm{C}$ until use.

RNA preparation of samples and RT-PCR. Total RNA was prepared from each specimen (both tissues and urine samples) using TRIzol (Invitrogen Co., USA) according to the manufacturer's protocol, and quantitated by ultraviolet absorption. Tissues exhibiting RNA characterized by high quality $18 \mathrm{~S}$ and $28 \mathrm{~S}$ bands on ethidium bromide-stained gels were preferentially selected. cDNA was synthesized from $3 \mu \mathrm{g}$ total RNA using an RNA PCR Kit version 2 (Takara, Dalian, P.R. China) with random primers.

Heparanase and $ß$-actin primers were designed by Primers Software 5.0. The sequences of the primers for heparanase were 5'-TCACTGCCAACAACAACG-3' (sense) and 5'-AAGCCGAGTCTTCACCAC-3' (anti-sense), a 270-bp product. The sequences of the primers for $B$-actin were 5'-ACGTCTGCTGGAAGGTGGAC-3' (sense) and 5'-GGTACCACCATGTACCCAGG-3' (anti-sense), a 160-bp product. Internal controls and heparanase primers were supplied by Sheng Gong Bioengineering Co., P.R. China. All the primers were diluted to $10 \mathrm{pmol} / \mathrm{l}$. PCR reaction mixture $(50 \mu \mathrm{l})$ for heparanase was pro-denatured at $94^{\circ} \mathrm{C}$ for $2 \mathrm{~min}$, then amplified through 35 cycles, each amplification consisting of denaturation at $94^{\circ} \mathrm{C}$ for $45 \mathrm{sec}$, annealing at
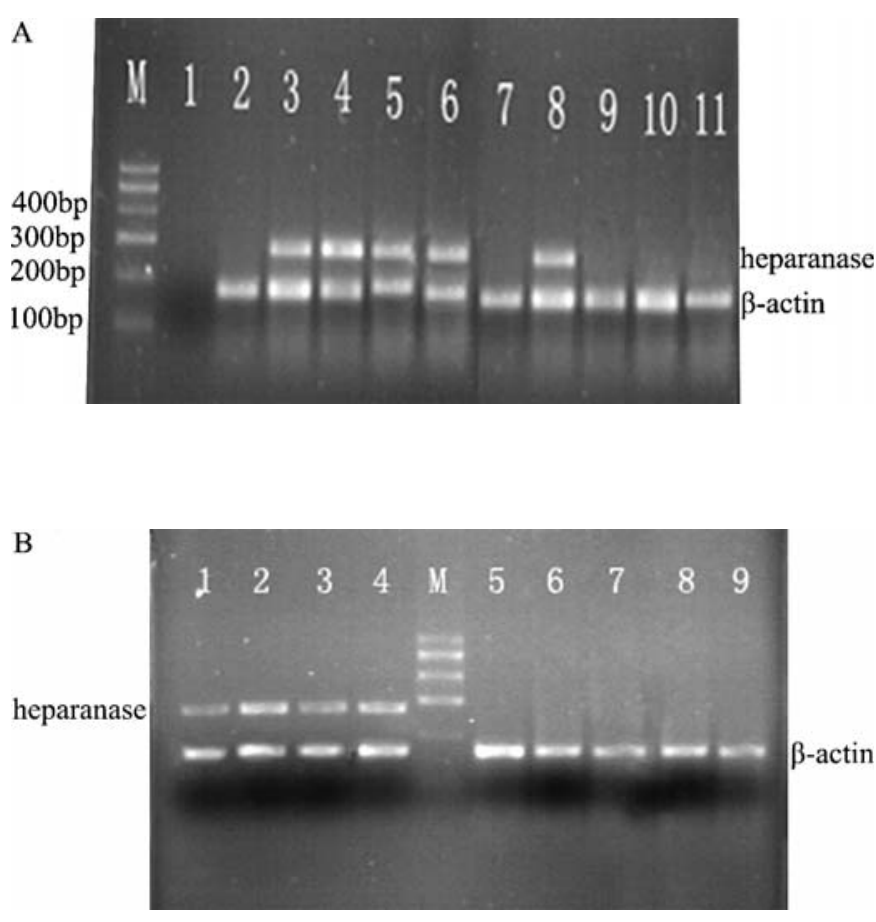

Figure 1. Detection of heparanase mRNA by RT-PCR in tissue and urine samples of bladder transitional cell carcinoma patients. The 270-bp upper line is heparanase, and the 160 -bp lower line is $B$-actin, $M$ is the marker. (A) Expression of heparanase in the tissues. Lanes 3-8, tumors; lanes 2 and 9-11, normal tissues; lane 1, blank control. (B) Expression of hepanase in urine. Lanes 1-4, tumor tissues; lanes 5-9, normal tissues.

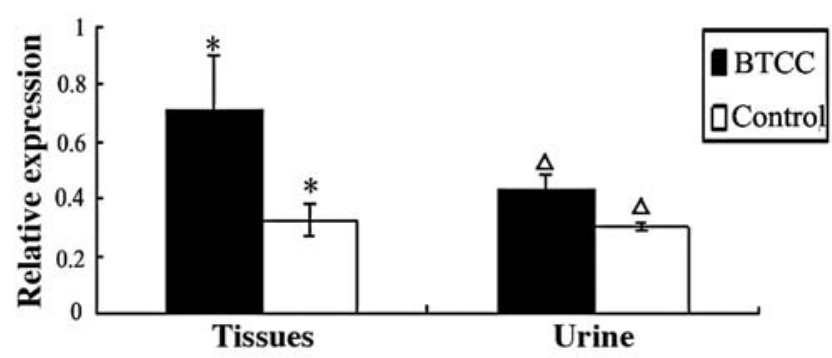

Figure 2. Relative expression of heparanase mRNA in the tissues and urine of bladder transitional cell carcinoma (BTCC). ${ }^{*}$ Tissues $\mathrm{t}=10.142, \mathrm{P}<0.01$; $\triangle$ urine $\mathrm{t}=8.912, \mathrm{P}<0.01$.

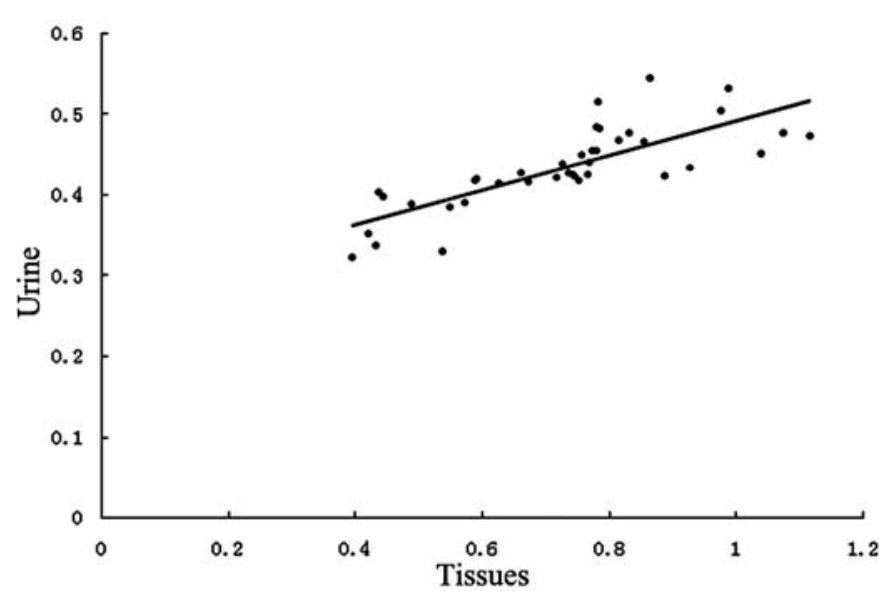

Figure 3. Relationship of heparanase mRNA between tumor tissue and urine samples. Correlation coefficient $r=0.786, \mathrm{P}<0.01$. 
Table I. Association between heparanase (HPSE) mRNA expression and clinicopathological factors in the tissues of bladder transitional cell carcinoma.

\begin{tabular}{|c|c|c|c|c|c|c|c|}
\hline Variables & No. & $\begin{array}{l}\text { Tissue HPSE mRNA } \\
\quad(\text { mean } \pm \text { SD })\end{array}$ & $\mathrm{F} / \mathrm{t}$ & P-value & $\begin{array}{l}\text { Urine HPSE mRNA } \\
\quad(\text { mean } \pm \text { SD })\end{array}$ & $\mathrm{F} / \mathrm{t}$ & P-value \\
\hline \multicolumn{8}{|l|}{ Stage } \\
\hline $\mathrm{T}_{\mathrm{a}-1}$ & 21 & $0.581 \pm 0.155$ & \multirow[t]{2}{*}{3.191} & \multirow[t]{2}{*}{$<0.01$} & $0.404 \pm 0.043$ & \multirow[t]{2}{*}{2.006} & \multirow[t]{2}{*}{$>0.05$} \\
\hline $\mathrm{T}_{2-4}$ & 34 & $0.759 \pm 0.183$ & & & $0.442 \pm 0.050$ & & \\
\hline \multicolumn{8}{|l|}{ Grade } \\
\hline $\mathrm{G}_{1}$ & 15 & $0.516 \pm 0.184$ & \multirow[t]{3}{*}{6.290} & \multirow[t]{3}{*}{$<0.01$} & $0.394 \pm 0.031$ & \multirow[t]{3}{*}{2.470} & \multirow[t]{3}{*}{$>0.05$} \\
\hline $\mathrm{G}_{2}$ & 27 & $0.766 \pm 0.167$ & & & $0.435 \pm 0.056$ & & \\
\hline $\mathrm{G}_{3}$ & 13 & $0.778 \pm 0.190$ & & & $0.447 \pm 0.041$ & & \\
\hline \multicolumn{8}{|l|}{ Gender } \\
\hline Male & 39 & $0.706 \pm 0.187$ & \multirow[t]{2}{*}{0.125} & \multirow[t]{2}{*}{$>0.05$} & $0.435 \pm 0.047$ & \multirow[t]{2}{*}{0.364} & \multirow[t]{2}{*}{$>0.05$} \\
\hline Female & 16 & $0.715 \pm 0.270$ & & & $0.428 \pm 0.061$ & & \\
\hline \multicolumn{8}{|l|}{ Age } \\
\hline$\geq 60$ & 32 & $0.718 \pm 0.180$ & \multirow[t]{2}{*}{0.434} & \multirow[t]{2}{*}{$>0.05$} & $0.434 \pm 0.053$ & \multirow[t]{2}{*}{0.261} & \multirow[t]{2}{*}{$>0.05$} \\
\hline$<60$ & 23 & $0.692 \pm 0.215$ & & & $0.430 \pm 0.048$ & & \\
\hline \multicolumn{8}{|c|}{ Tumor burden } \\
\hline$\geq 2 \mathrm{~cm}$ & 30 & $0.758 \pm 0.177$ & \multirow[t]{2}{*}{2.380} & \multirow[t]{2}{*}{$<0.01$} & $0.432 \pm 0.054$ & \multirow[t]{2}{*}{0.106} & \multirow[t]{2}{*}{$>0.05$} \\
\hline$<2 \mathrm{~cm}$ & 25 & $0.619 \pm 0.192$ & & & $0.434 \pm 0.045$ & & \\
\hline \multicolumn{8}{|c|}{ Multiplicity } \\
\hline Solitary & 24 & $0.567 \pm 0.207$ & \multirow[t]{2}{*}{3.789} & \multirow[t]{2}{*}{$<0.01$} & $0.438 \pm 0.040$ & \multirow[t]{2}{*}{0.775} & \multirow[t]{2}{*}{$>0.05$} \\
\hline Multiple & 31 & $0.782 \pm 0.210$ & & & $0.425 \pm 0.065$ & & \\
\hline \multicolumn{8}{|l|}{ History } \\
\hline Primary & 47 & $0.676 \pm 0.177$ & \multirow[t]{2}{*}{4.916} & $<0.01$ & $0.428 \pm 0.050$ & 1.851 & $>0.05$ \\
\hline Relapse & 8 & $0.949 \pm 0.119$ & & & $0.467 \pm 0.043$ & & \\
\hline Lymph nod & & & & & & & \\
\hline Positive & 12 & $0.843 \pm 0.167$ & 2.960 & $<0.01$ & $0.453 \pm 0.049$ & 1.619 & $>0.05$ \\
\hline Negative & 43 & $0.660 \pm 0.179$ & & & $0.424 \pm 0.050$ & & \\
\hline
\end{tabular}

$52^{\circ} \mathrm{C}$ for $45 \mathrm{sec}$ and extension at $72^{\circ} \mathrm{C}$ for $45 \mathrm{sec}$, followed by an extra extension at $72^{\circ} \mathrm{C}$ for $10 \mathrm{~min}$. The PCR profile for $B$-actin consisted of an initial denaturation of $2 \mathrm{~min}$ at $94^{\circ} \mathrm{C}$, followed by 31 cycles of a $45-\mathrm{sec}$ denaturation at $94^{\circ} \mathrm{C}$, a 45 -sec annealing at $57^{\circ} \mathrm{C}$ and a 45 -sec extension at $72^{\circ} \mathrm{C}$. PCR product $(10 \mu \mathrm{l})$ was analyzed on $1.5 \%$ agarose gel with ethidium bromide. Gel images were obtained using the Visage 2000 analysis system and analyzed with Basic Quantifier software (Bioimage, MI, USA). Fig. 1 shows the final RT-PCR products of heparanase and $B$-actin on a $1.5 \%$ agarose gel. The relative expression levels of heparanase were calculated as the density of the product of the repective target genes divided by that of $\beta$-actin taken from the same cDNA.

Cytological examination. All urine samples were centrifuged and stained according to the Papanicolaou method. At least 2 slides were prepared for each sample. The slides were screened under a microscope by cytologists and were reviewed and diagnosed according to current cytologic criteria and standard histologic terminology (8).
Statistical analysis. Statistical analysis included the $\chi^{2}$ test, one-way ANOVA, the correlation test and the t-test. All analysis was performed with SPSS ${ }^{\circledR}$ version 13.0. Results are representative of at least 2 independent experiments, and are expressed as the means \pm SD. Differences were considered statistically significant at $\mathrm{P}<0.05$.

\section{Results}

Expression of heparanase mRNA in the tissues and urine of bladder cancer. In the present study, heparanase expression was higher in bladder cancer tissues and urine than in the control groups (Fig. 2). The relative expression levels of heparanase in BTCC tissues and urine were $0.708 \pm 0.192$ $(76.4 \%, 42 / 55)$ and $0.433 \pm 0.051(70.9 \%, 39 / 55)$, respectively. There was a strong correlation between tissue and urine heparanase expression in the 55 TCCs, with a correlation coefficient of $\mathrm{r}=0.786$ ( $\mathrm{P}<0.01$, Fig. 3). As shown in Table I, significant differences in heparanase expression in the tissues were found in terms of clinicopathological factors, such as muscle invasiveness, grade, number, tumor burden and lymph 
Table II. Comparison of urine heparanase (HPSE) detection and urinary cytology.

\begin{tabular}{lrrrrrr}
\hline Groups & No. & \multicolumn{2}{c}{ HPSE mRNA } & \multicolumn{2}{c}{ Cytology } \\
\cline { 6 - 7 } \cline { 5 - 6 } & & \multicolumn{2}{c}{$(+)$} & $(-)$ & $(+)$ & $(-)$ \\
\hline BTCC & 55 & 39 & 16 & 21 & 34 \\
Benign control & 20 & & & & \\
Hematuria & 3 & 1 & 2 & 0 & 3 \\
UTI & 7 & 2 & 5 & 0 & 7 \\
BPH & 5 & 0 & 5 & 0 & 5 \\
Urinary stones & 5 & 0 & 5 & 0 & 5 \\
Normal & 20 & 0 & 20 & 0 & 20 \\
\hline
\end{tabular}

BTCC, bladder transitional cell carcinoma; UTI, urinary tract infection; BPH, benign prostatic hypertrophy.

node metastasis $(\mathrm{P}<0.05)$. Expression of heparanase in patients with recurrence and in patients with primary tumors was $0.949 \pm 0.119$ and $0.676 \pm 0.177$, respectively. The difference between these two groups of patients was significant $(\mathrm{P}<0.01)$. Furthermore, after a 2-year follow-up, the relapse rate in patients expressing heparanase was $41.6 \%$ (20/42), which was significantly higher than that observed in patients without heparanase expression $(7.7 \%, 1 / 13, \mathrm{P}<0.05)$. No correlation was found between heparanase mRNA expression and other clinicopathological factors. Unlike in the tissues, no significant relationship between urine heparanase expression and clinicopathological factors was observed.

Comparison of the detection of urine heparanase and urinary cytology. A comparison of urine heparanase expression and urinary cytology is shown in Table II. Of the 55 patients in the study, $39(70.9 \%)$ exhibited heparanase expression while only $21(38.2 \%)$ tested positive using urinary cytology $(\mathrm{P}<0.05)$. Though the sensitivity of urine heparanase expression was $70.9 \%$, its specificity was lower than that of urinary cytology $(92.5 \%)$. The positive predictive value of the RT-PCR assay for heparanase mRNA was $92.9 \%$.

\section{Discussion}

It is generally known that heparanase is one of the key enzymes involved in specifically degrading the HSPG component of the BM and ECM (9). Previous studies have demonstrated that heparanase up-regulation is well correlated with the metastatic potential of several different types of cancer, including pancreatic, head and neck, esophageal, gastric and colon cancer (10). In this study, our results demonstrate that heparanase mRNA was detectable in $76.4 \%$ of the BTCCs, and its expression was found to influence different malignant behaviors in BTCC, including stage, lymph node metastasis and tumor number. We demonstrated that heparanase mRNA expression was significantly higher in invasive bladder cancer at an advanced stage $\left(\mathrm{pT}_{2-4}\right)$. These findings suggest that heparanase expression may contribute to the progression of malignant solid tumors, and that it could serve as a diagnostic factor for BTCC. Furthermore, large tumor size and lymph node metastasis, which in themselves are a testimony to the survival capability of the tumor cells, have emerged as independent predictors of poor outcome for BTCC. In this study, those cases with larger tumors and lymph node metastases were more often heparanase positive than small non-metastasizing cases. Gilat found that $\mathrm{pH} 6.7$ was suitable for the activity of heparanase, whereas no heparanase activity was noted in a physiological environment (11). We supposed that the rapid tumor growth was easily sustained in an acid environment, resulting from necrosis due to a lack of blood supply, in which the activity of heparanase can be elevated.

In addition, the degree of histologic differentiation of TCC has been accepted as one of the most sensitive and independent factors of prognosis. As the tumor loses its differentiation, the chances of survival decrease (4). Significantly, in our research, as tumors became less differentiated, heparanase expression increased. This may be one of the reasons why histological tumor grade in TCC is a strong prognostic variable. Moreover, the relapse rate was significantly higher in the patients exhibiting heparanase mRNA expression than in the patients lacking it. Thus, heparanase expression is a promising prognostic factor for bladder cancer patients. However, studies involving large cohorts of patients are required to confirm this possibility.

High levels of heparanase have been detected in the urine samples of patients with aggressive metastatic diseases (12). The present study tried to optimize an RT-PCR protocol for the detection of heparanase mRNA in the urine of patients with bladder carcinoma, and to evaluate its usefulness as a sensitive non-invasive technique for the identification of shed malignant cells. Our findings indicate that heparanase mRNA is frequently observed in urinary sediments from patients with bladder cancer, but not in sediments from patients without bladder lesions. The detection of heparanase mRNA proved markedly more sensitive than conventional cytology, which only recognized $38.2 \%$ of the tumors. This high sensitivity is among the best reported using a single test. Previous studies, reviewed by Shafat et al, used ELISA assays for urine heparanase estimation and reported a sensitivity of $52.3 \%$ (13). In addition, our research indicated that the urine expression of heparanase had significant concordance with the tumor tissues, suggesting that the detection of heparanase mRNA expression in urine samples is a useful and non-invasive screening method for bladder cancer. However, we observed no significant relationship between urine heparanase expression and clinicohistological factors. The degradation of RNA in urinary sediment samples might be one of the reasons for these discrepancies.

The RT-PCR assay is an easy method for detecting mRNA expression in the tissues and urine of bladder cancer patients. Compared with other available techniques, such as the ELISA assay or multitargeted fluorescent in situ hybridization analysis, RT-PCR for heparanase mRNA is characterized by a superior combination of time and cost efficiency (14). Furthermore, although it lacks certain features provided by the aforementioned tests, such as the direct visualization of positive cells under the microscope, it appears to possess 
greater sensitivity and at least equivalent specificity. Finally, our analysis indicated that both positive and negative results produced by the heparanase mRNA RT-PCR assay are to be 'trusted', since the predictive values of the test reached $92.9 \%$.

Heparanase has become a prospective target in the treatment of human cancer as it is overexpressed in most tumors. Anti-heparanase strategies have been found to be effective in controlling tumor growth in vitro as well as in vivo (15). PI-88 is a mixture of highly sulfonated mannan oligo-saccharides, consisting of predominantly penta- and tetra-sized species isolated from the yeast pichia pastoris. It is currently being evaluated in multiple Phase II clinical trials as a monotherapy or in combination with standard chemotherapy for metastatic melanoma, non-small cell lung cancer, prostate cancer, postresection hepatocellular carcinoma and multiple myeloma (16). Heparin also has anti-heparanase activity and has been found to be influent in a number of animal models. While the use of heparin is limited by its anticoagulant properties, nonanticoagulant species of heparin have also been found to effectively inhibit tumor invasiveness and metastasis, and wound healing $(15,16)$.

In conclusion, our results indicate that heparanase plays a critical role in bladder cancer, and that it could serve as a new prognostic factor and target molecule for the inhibition of invasion and metastasis of this disease. Moreover, the results indicate that the RT-PCR assay for the detection of heparanase mRNA in urine samples may be a useful screening method for bladder cancer. In combination with cytological testing, it increases sensitivity and specificity and may contribute to the early detection of bladder cancer.

\section{References}

1. Kim WJ and Bae SC: Molecular biomarkers in urothelial bladder cancer. Cancer Sci 99: 646-652, 2008.
2. Xu D-L, Hu Y, Tang X, Liu J and Xia S-J: Expression of vascular endothelial growth factors mRNA in tissues and urinary exfoliative cells in transitional bladder caicinoma and clinical significance. Chin J Exp Surg 20: 1068-1070, 2003.

3. Niu HT, Xu T, Zhang YB, Pang DQ, Zhang ZL, Wu S, Cheng B, Wang Y, Chang JW and Sun G: Outcomes for a large series of radical cystectomies for bladder cancer. Eur J Surg Oncol 34: 911-915, 2008.

4. Droller MJ: Current concepts of tumor markers in bladder cancer. Urol Clin North Am 29: 229-234, 2002.

5. Vlodavsky I, Korner G, Ishai-Michaeli R, Bashkin P, Bar-Shavit R and Fuks Z: Extracellular matrix-resident growth factors and enzymes: possible involvement in tumor metastasis and angiogenesis. Cancer Metastasis Rev 9: 203-226, 1990.

6. Yanagishita M and Hascall VC: Cell surface heparan sulfate proteoglycans. J Biol Chem 267: 9451-9454, 1992.

7. Hulett MD, Freeman C and Hamdorf BJ: Cloning of mammalian heparanase, an important enzyme in tumor invasion and metastasis. Nat Med 5: 803-809, 1999.

8. Donald S: The cytologic diagnosis of malignant neoplasm in pleural and peritoneal effusions. Acta Cytol 31: 85-88, 1987.

9. Vlodavsky I, Goldshmidt O, Zcharia E, Metzger S, ChajekShaul T, Atzmon R, Guatta-Rangini Z and Friedmann Y: Molecular properties and involvement of heparanase in cancer progression and normal development. Biochimie 83: 831-839, 2001.

10. Ferro V, Hammond E and Fairweather JK: The development of inhibitors of heparanase, a key enzyme involved in tumour metastasis, angiogenesis and inflammation. Mini Rev Med Chem 4: 693-702, 2004.

11. Gilat D: Molecular behavior adapts to context: heparanase functions as an extracellular matrix degrading enzyme or as a $\mathrm{T}$ cell adhesion molecule depending on the local PH. J Exp Med 181: 1929-1931, 1995.

12. Shafat I, Zcharia E, Nisman B, Nadir Y, Nakhoul F, Vlodavsky I and Ilan N: An ELISA method for the detection and quantification of human heparanase. Biochem Biophy Res Commun 341: 958-963, 2006.

13. Shafat I, Pode D, Peretz T, Ilan N, Vlodavsky I and Nisman B: Clinical significance of urine heparanase in bladder cancer progression. Neoplasia 10: 125-130, 2008.

14. Halling KC and Kipp BR: Bladder cancer detection using FISH (UroVysion assay). Adv Anat Pathol 15: 279-286, 2008.

15. Dutta U and Poornachandra KS: Heparanase and gallbladder cancer: new insights into understanding tumor growth and invasion. J Gastroenterol Hepatol 23: 343-344, 2008.

16. McKenzie EA: Heparanase: a target for drug discovery in cancer and inflammation. Br J Pharmacol 151: 1-14, 2007. 